\title{
Quantitative assessment of melanomacrophage centres (MMCs) in dab Limanda limanda along a pollution transect in the German Bight
}

\author{
D. Bucke ${ }^{1}$, A. D. Vethaak ${ }^{2}$, T. Lang ${ }^{3}$ \\ 'Ministry of Agriculture, Fisheries and Food, Directorate of Fisheries Research, Fish Diseases Laboratory, 14 Albany Road, \\ Granby Industrial Estate, Weymouth, Dorset DT4 9TH, United Kingdom \\ ${ }^{2}$ Ministry of Transport and Public Works, Public Works Department, Tidal Waters Division, Section Ecotoxicology, \\ PO Box 20906, 2500 EX The Hague, The Netherlands \\ ${ }^{3}$ Bundesforschungsanstalt für Fischerei, Außenstelle Cuxhaven, Deichstr. 12, W-2190 Cuxhaven, Germany
}

\begin{abstract}
This study attempted to demonstrate whether an aspect of non-specific cellular immunity could be used as an indicator of fish health in populations of dab Limanda limanda exposed along a pollution gradient. Replicate samples of dab spleens were obtained during the Bremerhaven Workshop from a series of stations along a transect in the German Bight. Histochemical techniques, to demonstrate the components of the pigmented materials within melanomacrophage centres (MMCs), indicated varying amounts of breakdown cellular products (notably haemosiderin) to be present. The haemosiderin component was measured in each spleen section with the aid of a computerized image analyzer. Comparative results showed some inconsistencies in amounts of haemosiderin within MMCs between individual fish and replicated samples on stations. However, there were significant differences $(p<0.05)$ between stations overall, the amounts of haemosiderin being least at Stns 3 \& 9 . Although these results may indicate an effect of contaminants, no apparent correlation with disease prevalences in the dab population sampled could be established. The technique seems promising, but some problems are mentioned and discussed.
\end{abstract}

\section{INTRODUCTION}

The preceding paper in this MEPS SPECIAL, on the epidemiology of diseases in dab Limanda limanda along a transect through a polluted area of the German Bight (Vethaak et al. 1992), demonstrates that a number of diseases occur in these dab populations. Most of these diseases are known, or suspected, to have an infectious aetiology (examples are skin ulcers (bacterial), lymphocystis (viral) and epidermal papilloma (viral), but the aetiology of others is less clear). The purpose behind this present investigation was to determine whether one of the many non-specific defence mechanisms in fish is influenced to any extent by environmental contaminants.

Ellis (1980) reviewed the subject of non-specific defense mechanisms in fish, and described several defence systems. We chose to concentrate on the melanomacrophage centres (MMCs) which, depending on their degree of pigmentation, can reflect both the age and the health status of fish (Roberts 1975, Agius \& Agbede 1984). These MMCs appear as discrete aggregations of pigmented cells in spleen, as well as in kidney and to a lesser extent in liver of teleost fish (Agius 1980). Roberts (1975) proposed that the pigmented material in the MMCs consisted of varying amounts of melanin, lipopigments and haemosiderin, on the basis that the compounds could specifically be demonstrated histochemically. The origin and biochemical roles of these MMC constituents are not entirely clear, although it is known that haemosiderin (ferric iron) is stored in red blood cells. When effete red blood cells haemolyse, their breakdown products, including haemosiderin, are phagocytosed in the spleens by the macrophages. Similarly, macrophage phagocytic activity concentrates 'wear and tear' materials such as lipofuscin. This material consists of breakdown products formed by the oxidative polymerization of polyunsaturated fatty acids. Less is known about the role of melanin, except that it is increased in MMCs of stressed, 


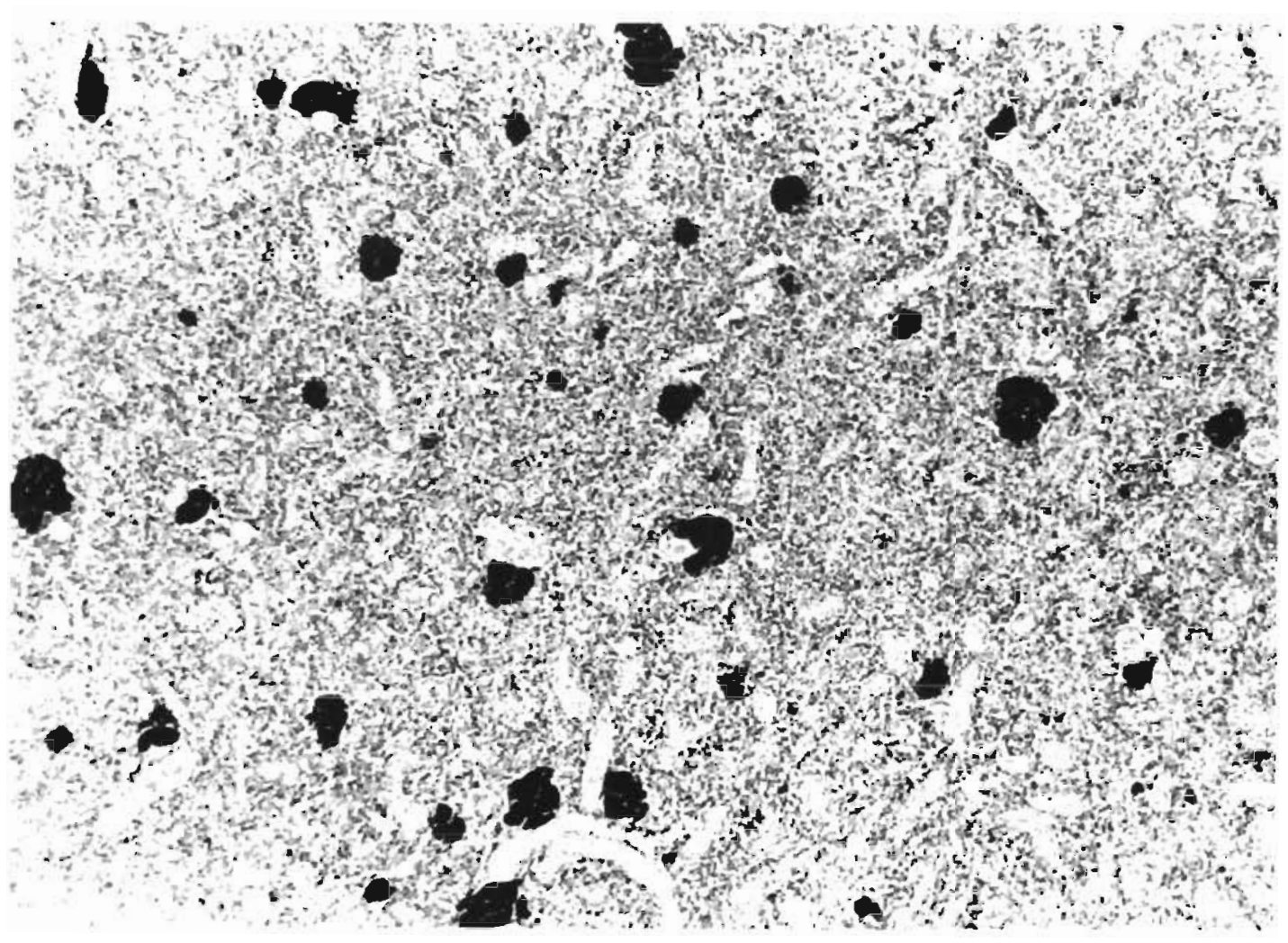

Fig 1 Limanda limanda $5 \mu \mathrm{m}$ section of dab spleen The dark staned areas represent pigment (haemosiderin) present in melanomacrophage centres Staned Perls' Prussian blue $\times 100$

starved and diseased fish (Aglus 1979. Aglus \& Roberts 1981) and has been claimed to have anti-bacterial properties (Edelstein 1971).

The role of MMCs as a non-specific defence mechanism has been previously investigated in natural stocks of North Sea dab (Bucke et al. 1984, Kranz 1989). Elsewhere, other workers have proposed this immunological response as a tool for biological effects monitoring (Wolke et al. 1985, Blazer et al. 1987). Any change in the amount of MMC activity in dab spleens should reflect stress-induced alterations of the phagocytic system as part of the non-specific cellular immune system.

The objective of the present study was to establish whether correlations exist between amounts of haemosidenn in spleens of dab from different stations, and the amounts of contaminants or the prevalence of dab diseases.

\section{MATERIALS AND METHODS}

Sampling of dab took place at six of the German Bight stations adopted by the Workshop on RV 'Walther Herwig', 22 to 26 March 1990. Spleens were dissected from a total of 5 apparently healthy female dab (length $>25 \mathrm{~cm}$ ) from each haul, with 2 to 4 hauls per station These spleens were pooled in batches of 5 and fixed in $10 \%$ formal-saline for subsequent routine histological processing, producing paraffin wax sections. The $5 \mu \mathrm{m}$ sectrons were stained with haematoxyIn and eosın ( $\mathrm{H} \& \mathrm{E}$ ), and subjected to Perls' Prussian blue reaction for demonstrating ferric iron (haemosiderin), Schmorl's reaction for lipofuscin and melanin, and Mallory's bleaching method for melanin (Bancroft \& Stevens 1975). Following visual examination of the sections with the aid of a light microscope, a quantitative assessment of melanomacrophage cell centres was made using a computerized image analyzer system (Olympus Cue 3 software; Olympus Optical Co. (UK) Ltd, 2-4 Honduras Street, London EC1Y OTX)

This quantitative assessment proceeded as follows: (1) Each haul was represented by 5 sections, one from each spleen. (2) Three fields from each spleen section were analysed for haemosiderin content. (3) Within each field, the percentage area occupied by material stanned with Perls' Prussian blue within MMCs was calculated, all stained objects $>3 \mu \mathrm{m}$ in diameter being included in the analysis. (4) The untransformed data were analysed statistically using a 2 way nested ANOVA to search for differences between stations. 


\section{RESULTS}

Visual examination of stained sections revealed that melanomacrophage cell centres were clearly defined in each spleen, but occurred in amounts which differed among individual fish, hauls and stations. It was not possible to make any assessment of MMCs based on those visual observations, nor to differentiate between amounts of material stained with Perls' Prussian blue (haemosiderin) and the brown-pigmented material stained with $\mathrm{H} \&$ E stain (Fig. 1). There were minimal amounts of Schmorl's-positive materials (lipofuscin and melanin) demonstrated in all spleens, a result confirmed with the melanin bleaching technique.

For quantitative analysis, haemosiderin was chosen as the best variable for measurement because of the high colour contrast produced with the Perls' Prussian blue reaction. Fig. 2 shows overall mean percentage areas of spleen sections occupied by haemosiderin at each station. No significant variability amongst hauls was found, but there were significant differences $(p<0.05)$ between stations. This was due to low values at Stns $3 \& 9$ compared to the remaining 4 stations. The spatial pattern of MMCs showed no apparent and consistent correlations with PCB concentrations in the liver of dab from the same populations (Cofino et al. 1992), nor with the prevalence of epidermal papilloma, lymphocystis, and skin ulcers (Vethaak et al. 1992).

\section{DISCUSSION}

The German Bight transect represented a pollution gradient with levels decreasing with distance offshore from Stn 3, where generally highest concentrations of

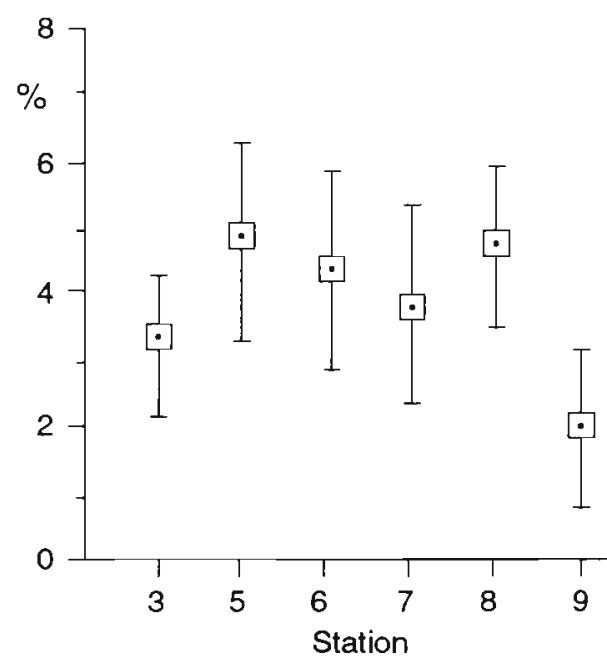

Fig. 2. Limanda limanda. Mean percentage areas $₫ \pm 95 \%$ confidence intervals) occupied by haemosiderin (within $\mathrm{MMCs}$ ) in sections of dab spleen from 6 stations along the German Bight transect micro-pollutants were measured (Cofino et al. 1992). In addition, elevated concentrations of some sediment contaminants and high prevalences of dab with skin ulcers were found at the outer transect Stn 9 . The areas occupied by haemosiderin in the splenic MMCs were least at Stns $3 \& 9$. It is possible that the observed spatial pattern is linked to a contamination-associated suppression of the non-specific immune system, perhaps a decrease in macrophage activity leading to a reduced concentration of splenic haemosiderin. This is in agreement with the studies of Weeks \& Warinner (1984), Weeks et al. (1986, 1988) and Rice \& Weeks (1989). The results from those investigations revealed that the phagocytic activity and chemotactic migration of isolated macrophages of fish from polluted waters is reduced. This is also in agreement with the in vivo studies showing the loss of viability in cells isolated from dab sampled along the German Bight transect (Lowe et al. 1992).

On the other hand, other workers have commented on correlations of MMCs with diseases and other measures of stress in individual fish. For example, Kranz (1989) found positive correlations between amounts of splenic haemosiderin and skin ulcers in dabs sampled from contaminated areas of the southern North Sea. Also, Secombes et al. (1991) recorded an increase in quantities in splenic (and kidney) MMCs in dab exposed to high levels of sewage sludge at a controlled experimental field site. These findings are, however, contradictory to our results.

The results could have been affected by migration of fish into and out of the areas sampled and by the spawning status of the fish (Rijnsdorp et al. 1992). It is quite possible that haemosiderin accumulates in MMCs over a long period of time and may not reflect short-term stress experienced by a fish as it briefly passes through an area of contamination. Thus, this simple method for measuring stress in fish has limited use as a marker of biological effects of contaminants in the open sea.

Our main conclusion is that the findings show promise, but do not prove the effectiveness of quantifying areas of MMCs (or even the haemosiderin component of the MMCs) as a tool for indicating the general health status of fish, at least not from a single sample, using low numbers of fish for analysis. We recognise that there is need for further studies, including experimental work, to determine the applicability of this method for biological effects monitoring.

\section{LITERATURE CITED}

Agius, C. (1979). The role of melanomacrophage centres in iron storage in normal and diseased fish. J. Fish Dis. 2: $337-343$ 
Agius, C. (1980). Phylogenic development of melano-macrophage centres in fish. J. Zool. (Lond.) 191: 11-31.

Agius, C., Agbede, S. A. (1984). An electron microscopical study on the genesis of lipofuscin, melanin and haemosiderin in the haemopoietic tissues of fish. J. Fish Biol. 24: $471-488$

Agius, C., Roberts, R. J. (1981). Effects of starvation on the melano-macrophage centres of fish. J. Fish Biol. 19: $161-169$

Bancroft, J. D., Stevens, A. (1975). Histopathological stains and their diagnostic uses. Churchill \& Livingstone, Edinburgh, London, New York

Blazer, V. S., Wolke, R. E., Brown, J., Powell, C. A. (1987). Piscine macrophage aggregate parameters as health monitors: effect of age, sex, relative weight, season and site quality in largemouth base (Micropterus salmoides). Aquat. Toxicol. 10: 199-215

Bucke, D., Watermann, B., Feist, S. (1984). Histological variations of hepato-splenic organs from the North Sea dab, Limanda Limanda (L.). J. Fish Dis. 7: 255-268

Cofino, W. P., Smedes, F., de Jong, S. A., Abarnou, A., Boon, J. P., Oostingh, I., Davies, I. M., Klungsøyr, J., Wilhemsen, S., Law, R. J., Whinnett, J. A., Schmidt, D., Wilson, S. (1992). The chemistry programme. Mar. Ecol. Prog. Ser. 91: $47-56$

Edelstein, L. M. (1971). Melanin: a unique polymer. Pathobiol. Ann. 1: 309-324

Ellis, A. E. (1980). Antigen-trapping in the spleen and kidney of the plaice, Pleuronectes platessa L. J. Fish Dis. 3: $413-426$

Kranz, H. (1989). Changes in splenic melano-macrophage centres of dab, Limanda limanda during and after infection with ulcer disease. J. Fish Dis. 6: 167-173

Lowe, D. M., Moore, M. N., Evans, B. M. (1992). Contaminant impact on interactions of molecular probes with lysosomes in living hepatocytes from dab Limanda limanda. Mar. Ecol. Prog. Ser. 91 135-140

Rice, C. D., Weeks, B. A. (1989). Influence of tributyltin on in vitro activation of oyster toadfish macrophages. J. Aquat. Anim. Health 1: 62-68

Rijnsdorp, A. D., Vethaak, A. D., van Leeuwen, P. I. (1992). Population biology of dab Limanda limanda in the southeastern North Sea. Mar Ecol. Prog. Ser 91: 19-35

Roberts, R. J. (1975). Melanin-containing cells of teleost fish and their relation to disease. In: Ribelin, W. E., Migaki. G. (eds.) The pathology of fishes. Univ. of Wisconsin Press, Madison, p. 399-428

Secombes, C. J., Fletcher, T. C., O'Flynn, J. A., Costello, M. J., Staff, R., Houlihan, D. F. (1991). Immunocompetence as a measure of the biological effects of sewage sludge pollution in fish. Comp. Biochem. Physicol. 100C: 133-136

Vethaak, A. D., Bucke, D., Lang, T., Wester, P. W., Jol, J., Carr, $M$. (1992). Fish disease monitoring along a pollution transect: a case study using dab Limanda limanda in the German Bight. Mar. Ecol. Prog. Ser. 91. 173-192

Weeks, B. A., Warinner, J. E. (1984). Effects of toxic chemicals on macrophage phagocytosis in two estuariene fish. Mar. environ. Res. 14: 327-335

Weeks, B. A., Warinner, J. E., Mason, P. L., McGinnis, D. S. (1986). Influence of toxic chemicals on the chemotactic response of fish macrophages. J. Fish Biol. 28: 653-658

Weeks, B. A., Warinner, J. E., Mlathews, E. S. (1988). Influence of toxicants on phagocytosis and melanin accumulation by fish macrophages. Aquat. Toxicol. 11: 424

Wolke, R. E., Murchelano, R. A., Dickstein, C. D., George, C. J. (1985). Preliminary evaluation of the use of macrophage aggregates (MA) as fish health monitors. Bull. environ. Contam. Toxicol. 35: 222-227 